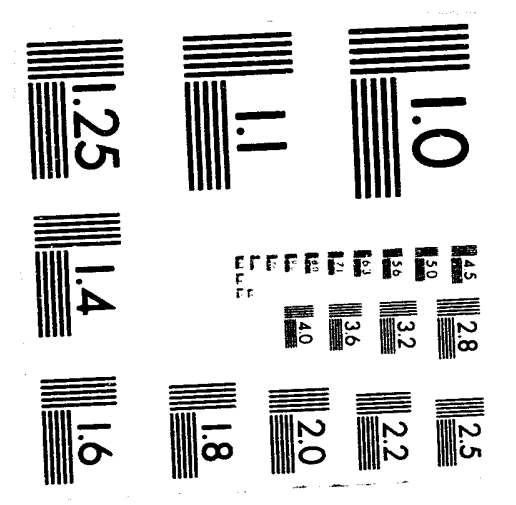



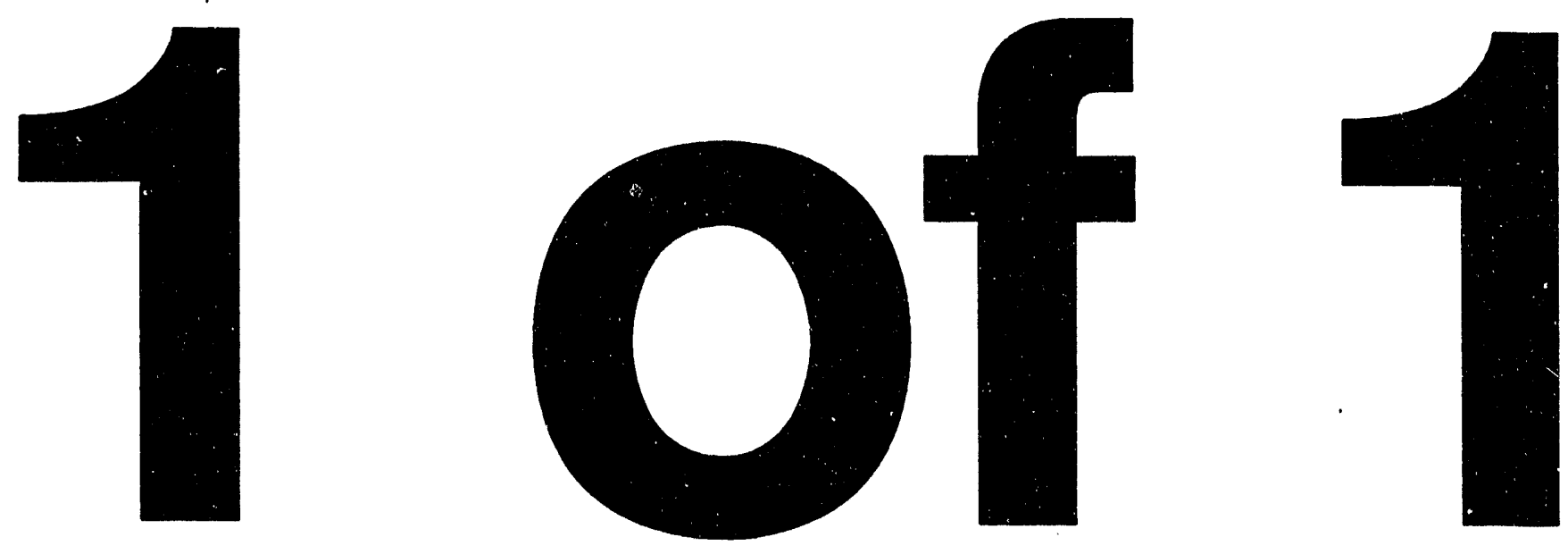
Kind of Report: Quarterly

Period:

September-December, 1993

Project Title: Large Scale Solubilization of Coal and Bioconversion to Utilizable Energy

$$
\text { DE-FG22-93PC } 93224
$$

PI:

\section{N.C. Mishra}

Department of Biological Sciences

700 Sumter Street, Coker Life Sciences Building

University of South Carolina

Columbia, South Carolina 29208

Telephone: (803) 777-5938

(803) $777-4002$

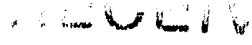

$13091 \%$
FAX:
031 


\section{Introduction}

In order to develop a system for a large scale coal solubilization and its bioconversion to utilizable fuel, we plan to clone the genes encoding Neurospora protein that facilitate depolymerization of coal. We also plan to use desulfurizing bacteria to remove the sulfur in situ and use other microorganisms to convert biosolubilized coal into utilizable energy following an approach utilizing several microorganisms (Faison, 1991). In addition the product of coal solubilized by fungus will be characterized to determine their chemical nature and the mechanism of reaction catalyzed by fungal product during in vivo and in vitro solubilization by the fungus or purified fungal protein.

\section{Main Objectives}

1. Cloning of Neurospora gene for coal depolymerization protein controlling solubilization in different host cells, utilizing Neurospora plasmid and other vector(s).

2. a. Development of a large scale electrophoretic separation of coal drived products obtained after microbial solubilization.

b. Identification of the coal derived products obtained after biosolubilization by Neurospora cultures or obtained after Neurospora enzyme catalyzed reaction in in vitro by the wildtype and mutant enzymes.

3. Bioconversion oi coal drived products into utilizable fuel. 
4. Characterization of Neurospora wildtype and mutant CSA protein(s) involved in solubilization of coal in order to assess the nature of the mechanism of solubilization and the role of Neurospora proteins in this process.

\section{Methods:}

Only experimental approach for objectives \#1 and \#2a are presented here since experiments were performed during this period in this area.

\section{Objective \#1 Cloning of gene for Neurospora CSA-protein}

The following methods will be used to clone the gene for Neurospora protein with coal solubilization activity (CSA).

\section{a. Cloning of Neurospora gene in yeast}

As yeast cannot solubilize coal this provides the easiest way to clone Neurospora gene by shortgun experiment in which Neurospora DNA segment (obtained after restriction enzyme digestion) will be ligated to pYEleu-2 plasmid and then introduced into $\mathrm{CaCl}_{2}$ treated competent pYEleu-2 yeast cells (Hinnen et al., 1978). The Leu $^{+}$yeast transformants will be examined for their acquisition of ability to solubilize coal in plate assays. The transformed yeast colonies containing the chimeric plasmid carrying Neurospora DNA segment encoding CSA-protein will be thus identified and further characterized. The success of this shortguntransformation experiment using yeast recipient cell will depend on the expression of the Neurospora gene encoding CSA protein in yeast cells. Since a number of heterologous genes have been expressed in yeast, it is therefore expected that Neurospora CSA protein gene could be expressed in yeast (Mishra, 1985; 1991). 
The wildtype Neurospora gene for CSA will also be directly cloned in Neurospora mutant cells deficient for CSA activity. In this approach wildtype Neurospora DNA will be shotgunned into a Neurospora plasmid pst $2.2 \operatorname{Ben}^{\mathrm{R}}\left(\mathrm{Ben}^{\mathrm{R}}\right.$ confers resistance to antibiotic benomyl); the chimeric plasmid will be used to transform Neurospora mutant lacking CSA (see Figure 2). First the Ben ${ }^{\mathrm{R}}$ transformants will be picked up by their ability to grow on plates containing benomyl and then these will be examined for coal solubilization activity (CSA).

\section{b. Identification of Neurospora CSA protein gene in a DNA library:}

In case the above approach to clone Neurospora gene in yeast or Neurospora cells is not successful, alternative methods will be used. The wildtype CSA protein has been purified in my laboratory. The purified wild type CSA protein obtained from the SDS PAGE (Laemmli, 1970) will be electroblotted onto Immobilon P, polyvinylidene diflouride (PVDF) membrane (Millipore Corporation, Bedford, MA) using the method of Matsudaira (1987). The membrane will then be given to Dr. Ishikawa of the Protein Microanalyses Facility of the Carolina Institute for Biological Research and Technology (IBRT), University of South Carolina, Columbia campus for microsequencing. Based on about the first nine amino acid sequences at the $\mathrm{N}$ terminus (Matsudaira 1987) or internal amino acid sequence (Huang, 1983), an oligonucleotide probe will be synthesized at the oligonucleotide synthesis facility of the USC IBRT facility located in our Department. This oligonucleotide probe will then be used to screen a cDNA library (as well as a genomic library of Neurospora) to identify the clone carrying Neurospora CSA protein gene.

Alternatively, immunoblotting will be used to identify clone with Neurospora CSA gene. We will prepare polyclonal antibody against the Neurospora CSA 
protein in rabbit. The antibody so prepared will be used to screen a Neurospora cDNA library to identify a clone carrying the gene for the Neurospora CSA protein. This method should work since the genes in the cDNA library are known to be expressed. Once the clone containing the gene for the Neurospora CSA protein is identified, the gene will be transferred to suitable vector such as pYELeu-10 or to Neurospora pstp 2.2, a mt DNA plasmid to which benomyl resistance $\left(\right.$ Ben $\left.^{\mathrm{R}}\right)$ gene has been added as a selectable marker (our unpublished results).

These chimeric plasmid containing the Neurospora CSA protein gene will be used to transform yeast cells or Neurospora (이) mutant cells (see Figure 2), which are devoid of ability to biosolubilize coal in vivo. The transformants will be identified by their ability to solubilize coal in vivo when assayed in Petri plates. The yeast or Neurospora transformants will be further examined for multiple copy of the CSA protein gene and for their possible autonomous existence by the method of Southern hybridization or by amount of the CSA protein produced.

The plasmids pYEleu-2 and pstp 2.2 and the genomic and CDNA libraries of Neurospora and PCR machine are available in my laboratory. All methods of molecular cloning, transformation, and identification and charcterization of transformants will be as practiced in my laboratory (Schablik et al., 1982; Almasan and Mishra, 1988; 1990; 1991) or as described previously (Hinnen et al., 1978; Maniatis et al., 1989; Yadav and Mishra, 1994; Feher and Mishra, 1994). 
Objective \#2. A. Development of a large scale electrophoretic separation of coal derived products obtained after microbial solubilization.

The coal solubilized by fungi or by fungal enzyme preparation will be loaded on a large gel electrophoresis sysitem of a dimension of $20 " \times 38$ " (Biorad). Agarose gel $(1.5 \%)$ will be poured into such gel system and then a large sample up to 10 grams of solubilized coal product will be loaded on such a gel system and then the different components will be separated by applying electric field for about 2-3 hours. Upon completion of electiophoresis the coal derived products rich in aromatic rings will be localized by visualization by electrophoresis and then isolated from the gel by electroelution or by just soaking the gel in water overnight and removal of gel or debris by filtration or centrifugation. The filtration or the supernatant will be further utilized by analysis of their chemical composition and for further fermentation by anaerobic microorganisms to yield utilizable energy fuel such as methanol or methane.

\section{Results}

Following experiments have been performed to achieve the proposed goals:

Objective 1: Confirmation of the coal solubilizing activity in the wildtype fungus and lack of such activity in the mutant strain.

A. The wildtype fungal strain (to be used as a source of donor DNA during construction of chimeric plasmid) and the recipient strain (to be used for the cloning and selection of transformant containing the chimeric plasmid with 
Neurospora CSA (coal solubilization activity gene)) were checked for their characteristic phenotypes with respect to their ability to solubilize coal. As seen in Figure 1 and 2, the wild type strain of fungus (Neurospora crassa) is able to solubilize coal (Figure 1); whereas the mutant strain is unable to solubilize coal (Figure 2). In these experiments coal granules were sprinkled over a week old fungal lawn in a Petri dish and then monitored for coal solubilization with 24-48 hours. Results of these experiments confirm that the wildtype strain has the gene to solubilize coal whereas mutant strain either lacks or has a defective gene for coal solubilization activities (CSA). Thus there has been no reversion or back mutation and that mutant phenotype is stable; we wanted to check this out before their use in molecular cloning experiments. Our results suggest that the DNA extracted from the wildtype strain can be used to construct a chimeric plasmid and then introduced into mutant cells and the later examined for the presence and expression of chimeric plasmid by its ability to solubilize coal upon introduction into mutant cells via transfection by chimeric plasmid.

B. Purification of Neurospora CSA protein. We have also started purification of the $84 \mathrm{Kdal}$ CSA protein from Neurospora in order to determine its $\mathrm{N}$ terminal or internal amino acid sequence or to prepare the antibody against this protein in rabbit. The amino acid sequence will be used to prepare the oligonucleotides to identify the clone carrying Neurospora CSA gene among cDNA orgenomic libraries. Alternatively, the antibody will be used to identify the clone carrying Neurospora CSA gene via immunoblotting. Even though 
Figure 1: Growth of the wildtype fungus strain showing coal solubilization activity (CSA). This strain will be used as source of CSA gene during molecular cloning.

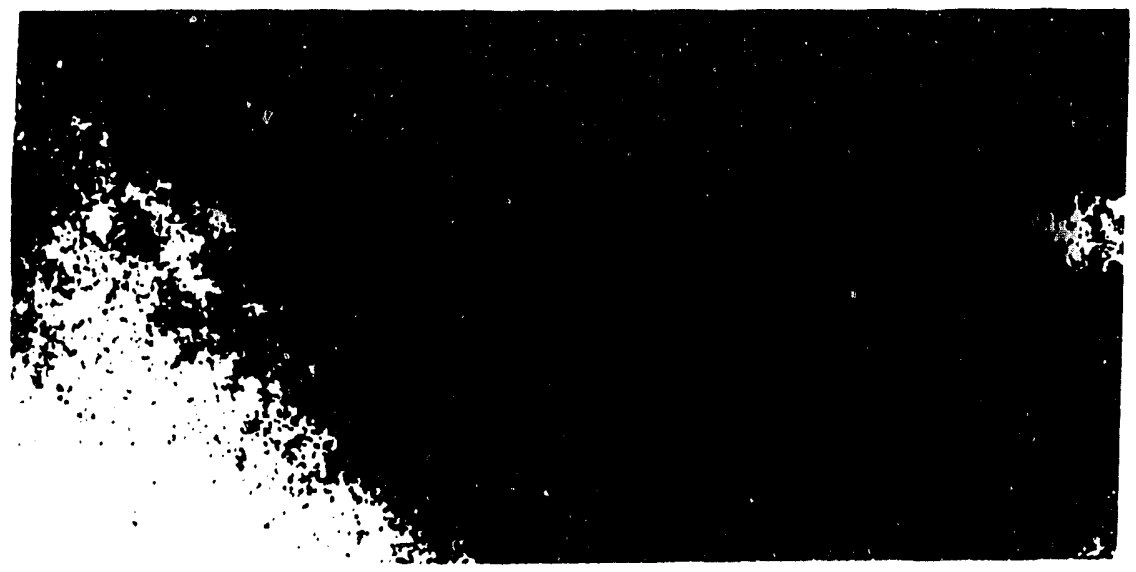

$\leftarrow$ solubilize coal granules on fungal lawn

Figure 2: Growth of the mutant strain showing lack of coal solubilization activity.

This strain will be used as recipient during transformation experiment to clone chimeric plasmid containing CSA gene.

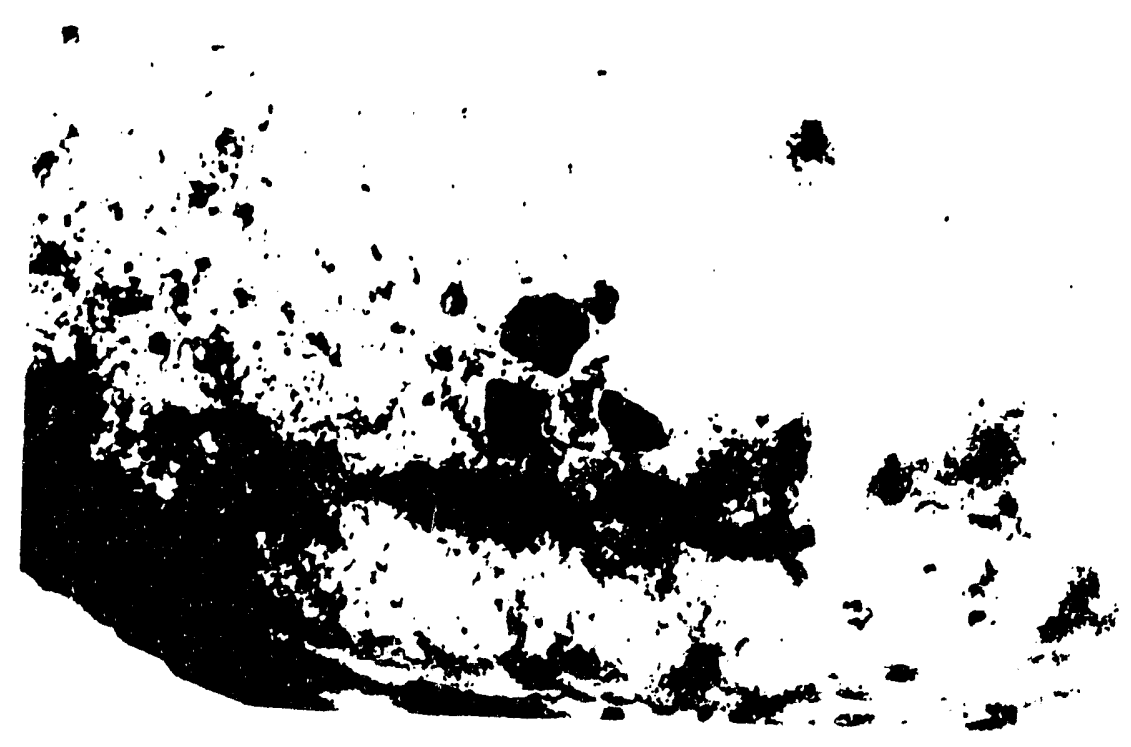

$\leftarrow$ Intact coal granules on fungal lawn 
this protein was purified in microscale in my laboratory by a previous graduate student (Brian Odom who worked on this aspect, has left, after receiving his Ph.D. to join as Assistant Professor at Mississippi Women's University). I have therefore attempted this purification of CSA protein on a large scale for determining the amino acid sequence of this protein for preparation of oligonucleotide probe and for raising antibody against this protein needed for use by future graduate students during the cloning of CSA gene. I am also trying to minimize the purification procedure by adopting ammonium sulfate precipitation steps. The ammonium sulfate precipitation may also help in separating the two CSA proteins, the $10 \mathrm{Kdal}$ and $84 \mathrm{Kdal}$. At present I have found that at $80 \%$ Ammonium Sulfate concentration, all Neurospora protein with CSA activity is precipitated. The CSA activity was checked by examining the ability of (ammonium sulfate precipitated) Neurospora protein to solubilize coal in vitro. The coal solubilization was monitored by increase in absorption at $254 \mathrm{~nm}$ due to release of UV absorbing material from coal added to the reaction mixture containing Neurospora protein. I have undertaken this short cut in purification of CSA protein encouraged by our recent success in purification of another difficult protein (Feher and Mishra, 1994).

Objective 2. Identification of the Nature of Products Solubilized by Neurospora. In order to determine the nature of the product in coal solubilized by Neurospora, I have started the separation of products via gel electrophoresis. An aliquat of the solubilized coal products was loaded on the $1 \%$ agarose gel. Upon 
electrophoresis, two groups of moving bands were separated; the fast moving band was identified as UV fluorescent band, whereas the slow moving group of band was identified as visible in white light.

The UV fluorescent band was found to show maximum absorption at $254 \mathrm{~nm}$ of light and was quantitated. There was no effect of proteases or nucleases upon this UV fluorescent band when incubated with either of these enzymes for up to 3 hours. These results suggest that the slow moving UV fluorescent band does not contain protein or nucleic acid and that the UV fluorescence is due to the presence of substances containing the aromatic ring. In addition to getting insight into the nature of the product in biosolubilized coal, I have carried these experiments to gain experience in handling the sample and to increase their yield during recovery from the gel after electrophoresis. At present the recovery is $10-20 \%$. We are trying different methods including electroelution to increase the recovery several fold so that we have enough material for further examination by NMR by our collaborators.

I have also arranged with Dr. Arthur Cohen, Professor of Geology, at the University of South Carolina to examine the extent of sulfur in biosolubilized coal before and after treatment with sulfur bacteria. Dr. Cohen is located in the same building as iny laboratory. This has resulted from an encounter during the last Christmas holidays.

Personnel: A good part of the effort during this period was directed towards recruitment of new graduate students to work on this DOE funded project. Initially an offer was made to Mr. M.D. Palkal; after months of waiting, he decided to join another univesity where his wife was also offered a position. Now we have 
recruited another graduate student, Mr. Ashish Patel, and offered a research assistantship to him. He has accepted the position and will join the project on April 16, 1994. Furthermore, we have recruited two undergraduate students, $\mathrm{Mr}$. Shawn Brasher and Ms. Tracy Scarborough (both biology majors), to work on the project under provision for undergraduate research experience credit at the University of South Carolina. They have joined my lab in January 1994 and are currently working on the project. Ms. Tracy Scarborough is supported by a scholarship from the Howard Hughes Foundation. Their contribution will be discussed in the next quarterly report. In addition to Mr. Ashish Patel, I have identified another graduate student and will make him an offer to join the project sometime this summer, as soon as Mr. Patel gets familiarized with the laboratory and gets going on the project.

\section{Literature References}

Almasan, A. and N.C. Mishra. 1988. Genetics 120, 935-945.

Almasan, A. and N.C. Mishra. 1990. Nucleic Acid Research 18:5871-5878.

Almasan, A. and N.C. Mishra. 1991. Proc. natl. Acad. Sci. U.S.A. 88:7689-7688.

Faison, B.D. 1991. Biological Coal Conversions. Critical Rev. in Biotech. 11:347366.

Feher, Z.S. and N.C. Mishra. 1994. Biochem. Biophys. Acta (in press).

Hinnen, A., J.B. Hicks and G.R. Fink. 1978. Proc. Natl. Acad. Sci. U.S.A. 75, 1229-1233.

Huang, H.V. et al. 1983. Methods in Enzymology 91, 318-324.

Laemmli, U.K. 1970. Nature 227, 680-685. 
Maniatis, T., E.F. Fritsch, and J. Sanbrook. 1989. Molecular cloning - a lab manual. CSH Press, Cold Spring, N.Y. Vol. 1-3.

Matsudaira, P. 1987. J. Biol. Chem. 262, 10035-10038.

Mishra, N.C. 1985. Gene Transfer in Fungi. Adv. Genetics. Vol. 23:73-178.

Mishra, N.C. 1991. Adv. Genetics 29, 1-62.

Schablik, M., A.M. Delange, A.A. Shums and N.C. Mishra. 1982. FEMS Microbiology 16:321-326.

Yadav, J.S. and N.C. Mishra. 1994. Eukaryotic vectors. Enclopedia of Biotechnology. 1-66 pages. VCH Publisher (in press). 

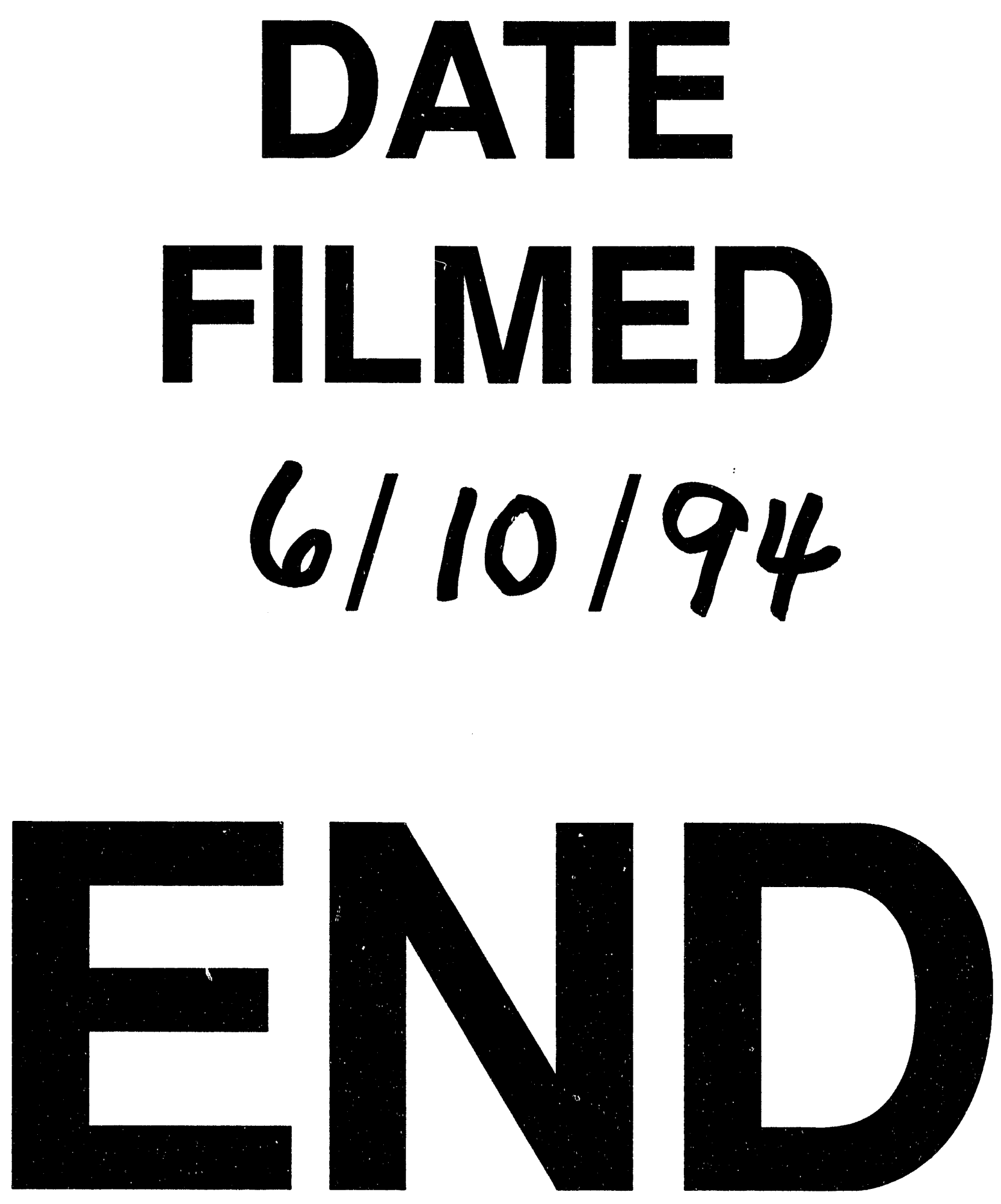
